OPEN ACCESS

Edited by:

J. B. Ruhl,

Vanderbilt University, United States

Reviewed by:

John Handmer,

International Institute for Applied Systems Analysis (IIASA), Austria

Daniel Farber,

University of California, Berkeley,

United States

*Correspondence:

Alpo Vuorio

alpo.vuorio@gmail.com

Specialty section:

This article was submitted to

Climate Risk Management,

a section of the journal

Frontiers in Climate

Received: 27 January 2021 Accepted: 30 April 2021

Published: 28 May 2021

Citation:

Vuorio A, Kovanen PT, Budowle B,

Sajantila A, Palo JU and Stoop J (2021) Wildfire-Related Catastrophes:

The Need for a Modern International Safety Investigation Procedure.

Front. Clim. 3:659437.

doi: 10.3389/fclim.2021.659437

\section{Wildfire-Related Catastrophes: The Need for a Modern International Safety Investigation Procedure}

\author{
Alpo Vuorio ${ }^{1,2 *}$, Petri T. Kovanen ${ }^{3}$, Bruce Budowle ${ }^{4}$, Antti Sajantila ${ }^{1,5}$, Jukka U. Palo ${ }^{1,6}$ and \\ John Stoop ${ }^{7}$ \\ ${ }^{1}$ Department of Forensic Medicine, University of Helsinki, Helsinki, Finland, ${ }^{2}$ Mehiläinen Airport Health Centre, Vantaa, \\ Finland, ${ }^{3}$ Atherosclerosis Research Laboratory, Wihuri Research Institute, Helsinki, Finland, ${ }^{4}$ Center for Human Identification, \\ University of North Texas Health Science Center, Fort Worth, TX, United States, ${ }^{5}$ Forensic Medicine Unit, Finnish Institute for \\ Health and Welfare, Helsinki, Finland, ${ }^{6}$ Forensic Genetics Unit, Finnish Institute for Health and Welfare, Helsinki, Finland, \\ ${ }^{7}$ Faculty of Technology, Policy and Management, Delft University of Technology, Delft, Netherlands
}

Despite the increased frequency and scale of wildfire-related catastrophes, there has been little or no effective and coordinated international policy to address their highly negative impact. Possibly a generalized approach to respond to such major events could be modeled on existing international safety investigation policies and agreements that already have proved successful. The International Civil Aviation Organization (ICAO) outlines safety investigations after international fatal aviation accidents. Although this well-established safety investigation protocol cannot be directly applied in acute wildfire-related accidents, it can offer a useful framework for establishing international guidelines to reduce risk of future wildfire catastrophes. The co-operation between safety investigation authorities has been shown to be fruitful especially for those less developed countries that have limited resources and experience related to accident investigations. While primarily an adaptive measure that can set practices to reduce vulnerability and fragility of ecosystems and human societies, the same policies could be seen as a climate change mitigation measure, as wildfires can contribute significantly to global $\mathrm{CO}_{2}$ emissions. Finally, the concept of independent and qualified safety investigations represents the principle of serendipity: disclosing by accident something that has not been foreseen. Feedback from reality compensates assumptions and limitations of feedforward analysis of complex systems that can only reveal their dynamics and performance in reality and over time.

Keywords: accident investigation, safety management system, aircraft, COVID-19, wildfire, $\mathrm{CO}_{2}$-emission

\section{INTRODUCTION}

Large-scale fires, such as those that raged across Australia during the "Black Summer" 2019-2020, can cause destruction both to the local ecosystems and global environment. The risk of wildfires is increasing as climate change progresses (Bowman et al., 2020, Figure 1). In addition, human lives have been lost and societies disrupted as a result of such fires. Rainforest fires have occurred periodically in Sumatra, Indonesia since the 1960s (Field et al., 2009), usually during the dry season when fires are set by farmers to clear waste. Although these rainforest fires cannot be considered traditional accidents in all respects, their unexpected overall effects have caused environmental disasters. In 2015 the Indonesian fire season was extremely severe. The $\mathrm{CO}_{2}$ equivalent biomass 


\section{0}

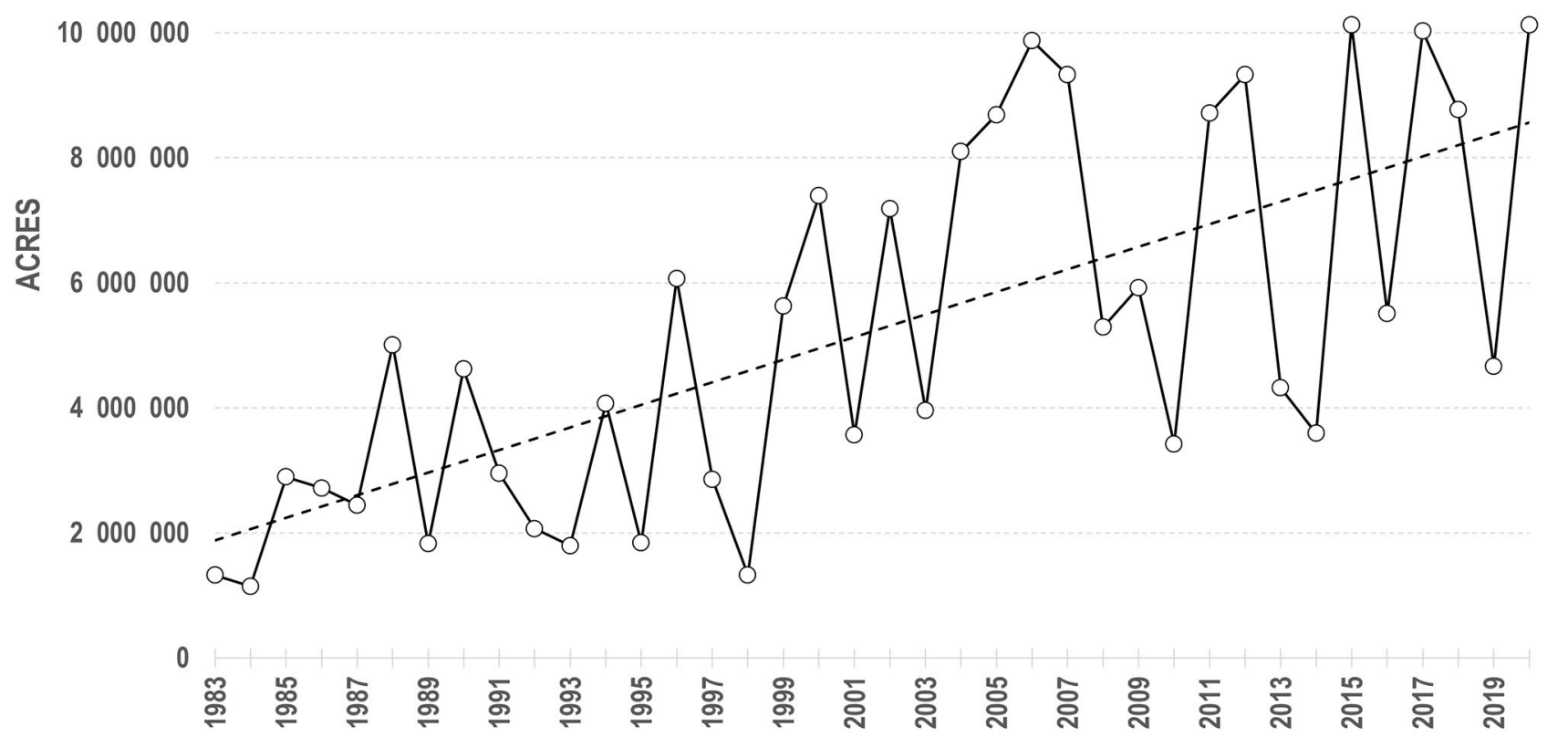

FIGURE 1 | Increasing trend of wildfires in the United States. The graph depicts the total area (in acres) affected by wildfires in the United States between the years 1983 and 2019. Data from the National Interagency Fire Center (www.nifc.gov).

burning emissions were estimated to be equal to the combined fossil fuel emissions generated by Japan and India in 2013 (Field et al., 2016).

In addition to ecosystem disturbance, wildfires can cause colossal economic losses. For example, in 2020 in the United States, there were about 57,000 wildfires compared with 50,477 in 2019 based on the statics provided by the National Interagency Fire Center (Insurance Information Office, 2021). These above-mentioned numbers also reveal that 10.3 million acres were burned in 2020, compared with 4.7 million acres in 2019. The costs of the Australian Black Summer have been estimated to exceed $\$ 100$ billion, including over $\$ 2$ billion of smoke-related health costs (Roach, 2020). As a result of wildfires, there are often disruptions in transportation and water and power supply lines. The health effects of wildfires have been clearly established (Stefanidou et al., 2008; Liu et al., 2019; $\mathrm{Xu}$ et al., 2020; Yu et al., 2020). Remarkably, during wildfire episodes, the concentrations of the smallest (even submicronsized) particles were increased (Makkonen et al., 2010). The small particles $(<2.5 \mu \mathrm{m})$ contain toxic trace elements and, as they can penetrate deep into the respiratory system, are the most harmful particles to human beings. A recent analysis of out-of-hospital cardiac arrest data for 5,336 individuals identified through the Cardiac Arrest Registry to Enhance Survival for 14 counties in California (2015-2017) showed that the risk of cardiac arrest increased with fire-related smoke exposure (Jones et al., 2020). Cheong and co-workers reviewed studies that had investigated the acute health impact of the Southeast Asian transboundary haze caused by forest fires and found increases both in the occurrence of acute myocardial infarction and in mortality due to out-of-hospital cardiac arrest (Cheong et al., 2019).

Thus, natural and human resources continue to be vulnerable to devastating events with serious consequences unless proactive measures are enacted. It is noteworthy that the Australian prime minister Scott Morrison in early 2020 called for a highlevel government inquiry into the response to the country's devastating bushfires (New York Times, 2020). Despite the increased scale of fire-related catastrophes and their effect on societies and the environment, there has been no effective and coordinated international policy to address these highly negative impacts. Furthermore, the current international agreements to prevent the increase of atmospheric $\mathrm{CO}_{2}$ do not consider ecological catastrophes which can contribute significantly to $\mathrm{CO}_{2}$ emissions (Rogelj et al., 2016). Proactive measures should be enacted.

The first version of Forensic Investigations of Disaster (FORIN) was published in 2010 and the second in 2016 presenting methodological approaches for forensic disaster investigations (Oliver-Smith et al., 2016). It is recognized in the FORIN 2016 edition that there is a need for additional application of the FORIN for disaster risk reduction and climate change adaptation. It highlighted that FORIN can be used to analyse root causes of risk factors helping to provide bases for policies and strategies to decrease future disasters. At this point, however, the guidance has been given at a general level, and there is clearly room for further development. 
We propose in this perspective article that international aircraft investigations, which have roots starting from the year 1944 have potentially significant guidance for FORIN incident investigation methodology in several areas (International Civil Aviation Organization, 2016). First and foremost, the most important principle of international aircraft investigation is that it is blame-free (Dekker and Breakey, 2016). Our proposed approach attempts to mollify the blame game. In the current FORIN protocol, there is an effort to start to analyse legal capabilities. In aircraft accidents investigation and legal processes are independent. Secondly, international aircraft accident investigation has a clear protocol by which stakeholders and shareholders participate in the investigation process (International Civil Aviation Organization, 2016). The current forensic investigation of the disaster management system would benefit from an international coalition to address solutions because there may be substantial conflicts of interest with government officials and what could be best practices to reduce future fires. An international approach may mitigate some of the conflicts of interest. Some fire-related issues may prove to be politically complex and challenging, but on the other hand, there is already evidence that progress has also been made in mitigating the impact of wildfires through international cooperation and knowledge exchange (van Lierop and Moore, 2016). This type of guidance is still not yet well-established in FORIN. Thirdly, climate changerelated disasters like wildfires are very complex events. Aircraft investigation offers systematic approach techniques to analyse complex interactions (Dekker et al., 2011). In the FORIN protocol, there is an attempt to find the root cause. However, in complex investigations often several causes emerge, and in certain circumstances, it is very difficult to define a single root cause. Fourthly, safety investigation offices need to be juristically independent, and they need sufficient governmental funding (International Civil Aviation Organization, 2016). Both of these conditions are essential to the success of accident investigation. There is also long-term experience of international co-operation between safety authorities in different countries. This relationship can be beneficial for those less developed countries that may have limited resources and experience. These various elements still need to be developed for forensic disaster investigations.

\section{LACK OF SAFETY INVESTIGATION PROTOCOLS AND WILDFIRES}

Considering the wildfire events, there is a clear need to develop better outcomes that will identify fragile systems (i.e., the most ones at high risk to suffer from devastating fires), reduce the exposures that impact human health, and also protect from significant resource losses. This kind of a generalized approach for the development of better outcomes could be modeled on other international safety investigation policies and agreements that have proved successful. Currently, for example in Indonesia, the responsibilities for forests are divided between several ministries leading to governmental inactivity in wildfire emergencies (Burki, 2017). In some other countries, such as Australia, major wildfires have led to public inquiry (Inspector-General for Emergency Management, 2020). While one of the aims of the public inquiry is to prevent future catastrophes, as is done in safety investigations, the nature of public inquire is more like a review of events; systematic analysis which could be provided by safety investigation is mostly lacking (Sulitzeanu-Kenan, 2010; Underwood and Waterson, 2013).

Recently, De Sisto and Handmer (2020) suggested the creation of an ongoing and continuously improving learning culture, in which daily based investigative knowledge and experiences are shared at the agency level. Unfortunately, however, such learning mode by co-operation is still missing. One plausible framework is provided by the International Civil Aviation Organization (ICAO): the safety investigations that can be carried out after international fatal aviation accidents, based on the ICAO-approved Annex 13 to the Convention on International Civil Aviation in 1944, and subsequent regular updates (International Civil Aviation Organization, 2016). Indeed, this agreement has demonstrated its effectiveness in improving aviation safety substantially. Therefore, it is reasonable to pose the question of whether international aircraft safety investigation processes would apply to environmental accidents, such as wildfires, and if implemented could they reduce risk and vulnerability to natural resources and human health in those fragile environments where devastating fires are more probable. The overall principle is the same: to prevent similar catastrophes from occurring again and again, or to provide more effective response mechanisms to manage the event and thereby reducing its severity. Importantly, the investigation is carried out not to determine liability, but to develop recommendations of proactive approaches for the prevention of future accidents i.e., learning from previous experience to reduce the risk and vulnerability constructively. These principles have been accepted as a part of European Union directives; thus, international support has been gained (European Union, 2010).

Typically, in aviation accidents, a final report is published within 12 months of the event, but in exigent circumstances, a safety investigation team can report preliminary recommendations much earlier. An example of the recommendations in a preliminary report being expeditiously and widely promulgated was the case of a lithium battery fire in a Boeing 787 aircraft in Boston in 2013. This report led to the worldwide grounding of all Boeing 787 aircrafts to prevent further accidents until the underlying cause was identified and appropriate corrective actions were implemented (National Transportation Safety Board, 2013). We proposed a similar application within the international chemical industry, which lacks a review process despite the occurrence of largescale catastrophes such as the methyl isocyanate gas leak at a pesticide plant in Bhopal, India in 1984 (Vuorio et al., 2017). Of note, an aviation safety investigation also examines the health issues associated with an accident (International 
Civil Aviation Organization, 2012) and thus could address the morbidity and mortality due to methyl isocyanate exposure in Bhopal.

\section{EVOLUTION OF SAFETY INVESTIGATIONS}

Safety investigations have seen a gradual evolution in scope and methodology. Safety investigations in aviation were conducted in the United States by the National Transport Safety Board (NTSB) in a multimodal context, based on a legally assured independence from governmental interference (National Transportation Safety Board, 2021). The NTSB conducts its investigative efforts in an independent federal institute, combining all modes of transportation: air, maritime, rail, roads and pipelines. Gradually, the NTSB expanded its scope to victims, family assistance, training of investigators, and event-driven occasionally also to other industrial sectors, such as space and civil infrastructures.

In aviation, the focus during investigations is gradually widening from preventing similar events to improve understanding of the system itself in its behavioral variety, assumptions and limitations, including responding and recovery from destabilizing events. The AF447 case [Bureau d'Enquêtes et d'Analyses (BEA), 2012] revealed fundamental deficiencies in man-machine interfacing, while the B737MAX cases (The House of Committee on Transportation Infrastructure, 2020) disclosed the limitations of certifying disruptive adaptations with derivative certification procedures. Their accidents can be traced back to system properties that did not manifest themselves before as catastrophic and have become foreseeable instead of inevitably being labeled as "emergent" properties. Safety investigations serve the category of "low probability/high consequences" beyond statistical confidence in predicting failure of more frequent, foreseeable events. The concept of independent safety investigations represents the principle of serendipity: disclosing by accident something that has not been foreseen. Feedback from reality compensates assumptions and limitations of feedforward analysis during the design and certification of complex systems that can only reveal their dynamics and performance in reality (ESReDA, 2020).

The NTSB served as a role model for independent investigations, establishing European and other world regional counterparts. Together with its Scandinavian, Canadian and Dutch counterparts, it participated in ITSA, a forum of legally independent, national investigative authorities established in 1993 to learn from each other and to exchange experiences (ESReDA, 2020). A major breakthrough was achieved by posing the question in sharing not what to investigate, but how to investigate. This approach enabled each investigative agency to remain independent from its legal and institutional context and simultaneously achieve a high-level playing field concerning tools, techniques and above all, a common methodology, irrespective of mode, sector or domain. Such a methodology discriminates three phases of the investigative process, each with its specific goals, principles and deliverables. These phases are (ESReDA, 2020):
- Investigative reconstruction, based on forensic principles and techniques for collecting raw data, on-site and off-site. This phase makes the step from description to explanation of the event.

- Analytic interpretation, mobilizing (multi-)disciplinary knowledge and sectoral, specific expertise and experience enables the step from understanding the event into understanding the system and intervention in the system throughout its life cycle and levels.

- Adaptive intervention, based on input from the previous steps, applies engineering design and system change management principles, enabling the transition to sustainable change and feasible and credible safety enhancement.

These steps facilitate insight into the causal relations between events, interrelations between system components and functions and clarify dynamics and time dependence of phenomena. The gradual transition in focus from event to system during the investigation creates oversight over the system architecture, structure, culture and operational processes (Dekker et al., 2011). Identification of change drivers, change agents, and their underlying values and goals clarify the potentials for system change and adaptation. This approach also clarifies the dynamics of a system with respect to the presence of showstoppers, whistleblowers and change opportunities. It creates opportunities for foresight, predicting future safe performance. In doing so, the legacy nature and specifics characteristics of major systems put high demands and restrictions in developing this methodology for specific applications. Application of this investigative process elevates the investigations from a factor and actor-oriented scope-focusing on performance-to an additional focus on systemic properties and principles, aspects, change vectors, institutional arrangements, values and transition management strategies. A plausibility, feasibility and credibility assessment indicates which safety enhancement options are realistically implementable. Recommendations may focus on optimizing procedures, derivative from existing operational practices, on the introduction of disruptive system adaptations or even on prospective options for changing principles and concepts. Such strategies are case-based, evidence-based and above all, knowledge-based due to the in-depth analysis of the event that triggered a need for safety enhancement. The investigative process bears elements of serendipity: learning by accident something that has not been observed before. Safety investigations represent a specific category of analytical approaches. Generic, statistical analysis of data focuses on trends and patterns, (mono-)disciplinary research provides knowledge and understanding of specific phenomena, specific, conditional analysis of data serves policymaking for specific contexts and target group. Investigations link understanding of events to their systemic context and operating conditions. Safety investigations are the problem providers for knowledge development and system change. The analytic potential of investigations has gradually expanded the interest in understanding the behavior of earthquakes, tsunamis, bushfires and wildlife fires, and other major, low-frequency events without allocating blame and liability (ESReDA, 2020). 


\section{COMPARISON OF ADMINISTRATIVE PROTOCOLS BETWEEN AN INTERNATIONAL AIRCRAFT ACCIDENT INVESTIGATION AND THE PROPOSED INTERNATIONAL WILDFIRE INVESTIGATION}

Interestingly, some national initiatives regarding wildfires can be traced back to 1910 in the United States, although they were based on an economic rather than an ecological perspective (Silcox, 1910). The investigation of international air accidents began in 1944 with the adoption of Annex 13 of the Chicago Convention by the International Civil Aviation Organization (ICAO) (Stoop and Kahan, 2005). The motivation of the ICAO Annex 13 was to try to prevent similar accidents from occurring again without taking a position on legal liability. Often the safety investigations provide recommendations that suggest enactment of effective legislation addressing the root cause and mitigation of the cause of the event. A criminal investigation, if necessary, is a separate process independent of the safety investigation (Imam and Aspan, 2020). We propose, in an analogous manner, that an international wildfire accident investigation agreement could be developed with an intergovernmental agreement that possibly could be part of the Paris Climate Agreement. Also, guidance provided by the Food and Agriculture Organization (FAO) of the United Nations could be useful to identify the key elements of useful legislation on forest fires (Food and Agriculture Organization of the United Nations, 2009).

At the state level, the ICAO Annex 13 defines those stakeholders who take part in the investigation. Commonly, countries that have been involved in aircraft accident investigations have established accident investigation organizations. In many countries, these organizations are multipurpose; they investigate not only aircraft accidents, but also other major catastrophes that impact society and the environment. The number of permanent staff is rather limited but in the case of an acute investigation (e.g., a critical incident), additional specialists are hired temporarily. From the legal perspective, for example, in the European Union, the ICAO framework is part of the European Parliament Regulation (European Union, 2010), and international cooperation is at the heart of this regulation. During the investigation process, usually the country in which the accident occurred takes responsibility to coordinate the investigation process. The stakeholders (investigators/representatives) will be from the countries representing the aircraft or major aircraft component manufacturers, aircraft registration and deceased passengers. Regarding international wildfire safety investigations, these principles could be adopted as shown in Table 1.

The national accident investigation authorities could take on the responsibility of the investigation process also regarding wildfires. This investigation would probably be smoothly undertaken in countries having an established multipurpose accident investigation organization and having traditionally been accustomed to investigating different types of accidents. In countries where safety investigations have mainly focused on accidents involving specific modes of transport, special arrangements for wildfire investigations would be required. An agreement on the investigation of international wildfires, parallel to international air accident investigations, should sanction the participation of representatives from countries affected in the investigation process.

\section{COMPARISON OF TECHNICAL ASPECTS BETWEEN INTERNATIONAL AIRCRAFT ACCIDENTS AND PROPOSED INTERNATIONAL WILDFIRE INVESTIGATIONS}

The investigation process in use in aviation has developed based on experience gained over decades. Similarly, the development of a wildfire safety investigation will take considerable time to gather experiences and develop best practices. As a useful example in aviation accidents pre-accident data gathered from flight data recorder and cockpit voice recorder can be used and combined with pilot performance analysis received from airborne image recorders (Li et al., 2020) to assist the investigation to determine the factors to address to reduce risk and vulnerability.

Regarding wildfire safety investigations satellite-based measurement technology can be applied to assist in determining causes of an event, conditions affecting the severity of the outcome in terms of damage to ecosystems and human society as well as potential remediation. Furthermore, this would allow the measurement and analysis of wildfire-caused emissions (Li et al., 2000; Jang et al., 2019; Hislop et al., 2020). The satellite-based emission measurements combined with fire activity and vegetation productivity have been successfully applied internationally in the Global Fire Emission Database (2021). These data provided by the Global Fire Emission Database include (1) burned area (Giglio et al., 2013), (2) carbon and dry matter emissions (van der Werf et al., 2017), (3) fractional contribution of various fire types of total emissions and (4) list of emission factors to compute trace gas and aerosol emissions (Akagi et al., 2011).

\section{DISCUSSION}

We propose in this perspective article that wildfire accident investigations could apply safety investigation process principles which potentially can model methodological and legal bases provided by the ICAO Annex 13 based aircraft accident investigation process. It is not, however, possible to "copy-and-paste" this protocol because each system has different requirements and features and much remains to be done in developing a specific international protocol for wildfire safety investigations. However, there are examples of successful forensic investigations of disasters that are related to environmental change caused by humans. One interesting investigation is related to analyzing vulnerabilities in society and the environment that increase climatological hazards (Stonich, 2021). This comprehensive investigative analysis well combines 
TABLE 1 | Comparison of administrative protocols between current international aircraft and proposed forest fire accident investigations.

\begin{tabular}{|c|c|c|}
\hline Issue & Existing aircraft accident investigation protocol & Proposed wildfire investigation protocol \\
\hline International Agreement & ICAO Annex 13 Chicago Convention & $\begin{array}{l}\text { Additional protocol of Paris Climate Agreement in } \\
\text { co-operation with } \mathrm{WHO} \text { and } \mathrm{FAO}\end{array}$ \\
\hline State-level legislation & State-level and alliances-wide legislation & State-level and alliances-wide legislation \\
\hline Investigation authority & $\begin{array}{l}\text { National accident investigation authorities of the country of } \\
\text { accident occurrence }\end{array}$ & $\begin{array}{l}\text { National accident investigation authorities with temporarily } \\
\text { hired professionals from the country where fire occurs }\end{array}$ \\
\hline $\begin{array}{l}\text { Stakeholders in the investigation } \\
\text { process } \\
\text { Investigation }\end{array}$ & $\begin{array}{l}\text { Countries representing aircraft or major aircraft component } \\
\text { manufacturers, aircraft registration and deceased passengers } \\
\text { Independent and conducted without prejudice to any } \\
\text { judicial action }\end{array}$ & $\begin{array}{l}\text { Countries representing countries of fire occurrence or countries } \\
\text { having environmental and/or health impact due to fire } \\
\text { Independent and conducted without prejudice to any } \\
\text { judicial action }\end{array}$ \\
\hline
\end{tabular}

WHO, World Health Organization; FAO, Food and Agriculture Organization of the United Nations.

the impact of ecological and political issues on the vulnerability of society.

Safety investigation processes related to forest fire catastrophes are likely to be more complex especially if they are related to additional accidents (Beresford et al., 2021). However, aircraft investigations may be complex in addition to matters relating to the airplane itself. For example, El Al Flight 1862 crashed into the neighborhood of Amsterdam on 4 October 1992 destroying an entire block of flats and killing several people on the ground (Netherlands Aviation Safety Board, 1992).

However, similar overarching quality systems may be applicable, focusing on identifying and implementing solutions based on experience and continuous improvement (International Civil Aviation Organization, 2016; Oliver-Smith et al., 2016). The fundamental elements of the safety (or perhaps mitigation) investigation process are: (1) investigator independence, which requires establishing international agreement to investigate acute environmental catastrophes (International Civil Aviation Organization, 2016); (2) a holistic conceptual process for examining accidents (Dekker et al., 2011); (3) an established, international institutional framework to provide investigator resources for large-scale catastrophes (International Civil Aviation Organization, 2016); and (4) continuous and sustainable training of competent investigators supported by governments (Vuorio et al., 2017).

Although the aviation accident safety investigation protocol cannot be replicated when designing a protocol for acute wildfirerelated accidents, it provides a useful framework to establish international guidelines for response and reference to use a similar process to develop approaches to reduce the number and severity of future catastrophes. Transformational rather than incremental changes in current thinking and practice are needed to address the impact of wildfire-related catastrophes on local and global environments, as well as on human, animal and plant health, and to protect the basic functions of society (Kates et al., 2012). Analysis of risk and vulnerability of systems can inform on changes and properties and the emergent consequences could contribute to a better understanding of how and why wildfires develop into disasters (Oliver-Smith et al., 2016).

The implementation of a wildfire investigation procedure could rely on an approach in which the importance of health is integrated into the environmental systemic impact of wildfire
(Briggs, 2008). In fact, a recent review shows that there is an increasing interest to develop tools that can take care of health issues in mitigation within the climate change adaptation strategies (Delpla et al., 2021). This inclusion in wildfire-related catastrophes investigations may help to decrease morbidity and mortality, and it certainly can be a force multiplier to promote implementation.

It is noteworthy that, in addition to large-scale wildfires, it is possible to apply aviation accident investigation techniques to other large-scale disasters. The current coronavirus disease (COVID-19) pandemic is reminiscent of previous epidemics that inspired the system of air safety investigations. Dr. John Snow's investigation of the cholera epidemic in London in 1854 provided a basis on how to investigate such devastating events. He was the first to apply the precautionary principle and is considered the father of epidemiology. His example demonstrates the importance of exploring the association between a cause and an effect even without a theoretical understanding of the association (Goldstein, 2012). Since those days, global interactions have become increasingly more complex. The challenge will be to use modern accident investigation procedures to improve global safety systems.

\section{CONCLUSION}

Despite the increased frequency and scale of wildfire-related catastrophes, there has been little or no effective and coordinated international policy to address their highly negative impact. Possibly a generalized approach to respond to such major events could be modeled on existing international safety investigation policies and agreements that already have proved successful. At present, there are ongoing interests in the development of forensic disaster investigation protocols. The second edition of FORIN was published in 2016 (Oliver-Smith et al., 2016). Yet, forensic investigations protocols can be considered relatively nascent compared with international aircraft accident protocols which were introduced already in 1944 . It could be very fruitful to leverage some of the experiences and practices of the aircraft accident investigation protocols and investigations especially when creating specific protocols for international wildfire-caused disasters. 
Such newly created protocols and policies are primarily adaptive measures that can set practices to reduce the vulnerability and fragility of ecosystems and human societies. Since the wildfires contribute significantly to global $\mathrm{CO}_{2}$ emissions, the same policies can be considered also as climate change-mitigating measures. Finally, the concept of independent and qualified safety investigations represents the principle of serendipity: disclosing by accident something that has not been foreseen. Feedback from reality compensates assumptions and limitations of feedforward analysis of complex systems that can only reveal their dynamics and performance in reality and over time.

\section{REFERENCES}

Akagi, S. K., Yokelson, R. J., Wiedinmyer, C., Alvarado, M. J., Reid, J. S., Karl, T., et al. (2011). Emission factors for open and domestic biomass burning for use in atmospheric model. Atmos. Chem. Phys. 11, 4039-4072. doi: 10.5194/acp-11-4039-2011

Beresford, N. A., Barnett, C. L., Gashchak, S., Kashparov, V., Kirieiev, S. I., Levchuk, S., et al. (2021). Wildfires in the chornobyl exclusion zone - risks and consequences. Integr. Environ. Assess. Manag. doi: 10.1002/ieam.4424. [Epub ahead of print].

Bowman, D. M. J. S., Kolden, C. A., Abatzoglou, J. T., Johnston, F. H., van der Werf, G. R., and Flannigan, M. (2020). Vegetation fires in the Anthropo- cene. Nat. Rev. Earth Environ. 1, 500-515. doi: 10.1038/s43017-020-0085-3

Briggs, D. J. (2008). A framework for integrated environmental health impact assessment of systemic risks. Environ. Health. 7:61. doi: 10.1186/1476-069X-7-61

Bureau d'Enquêtes et d'Analyses (BEA) (2012). Final Report on the accident on 1st June 2009 to the Airbus A330-203 registered F-GZCP operated by Air France flight AF 447 Rio de Janeiro - Paris. Available online at: http://www.aaiu. ie/sites/default/files/FRA/BEA\%20France\%20Accident\%20Airbus\%20A330203\%20F-GZCP\%20AF447\%20Atlantic\%20Ocean\%2001-06-2012_opt.pdf (accessed April 15, 2021).

Burki, T. K. (2017). The pressing problem of Indonesia's forest fires. Lancet Respir Med. 5, 685-686. doi: 10.1016/S2213-2600(17)30301-6

Cheong, K. H., Ngiam, N. J., Morgan, G. G., Pek, P. P., Tan, B. Y., Lai, J. W., et al. (2019). Acute health impacts of the Southeast Asian trans boundary haze problem-a review. Int. J. Environ. Res. Public Health. 16:3286. doi: 10.3390/ijerph16183286

De Sisto, M., and Handmer, J. (2020). Communication: the key for an effective interagency collaboration within the bushfire investigation network. Int. J. Emerg. Serv. 9, 299-312. doi: 10.1108/IJES-04-2019-0020

Dekker, S., and Breakey, H. (2016). "Just culture": improving safety by achieving substantive, procedural and restorative justice. Saf. Sci. 85, 187-193. doi: 10.1016/j.ssci.2016.01.018

Dekker, S., Cillers, P., and Hofmeyer, J.-H. (2011). The complexity of failure: implications of complexity theory for safety investigations. Saf. Sci. 49, 939-945. doi: 10.1016/j.ssci.2011.01.008

Delpla, I., Diallo, T. A., Keeling, M., and Bellefleur, O. (2021). Tools and methods to include health in climate change adaptation and mitigation strategies and policies: a scoping review. Int. J. Environ. Res. Public Health 18:2547. doi: 10.3390/ijerph18052547

ESReDA (2020). Enhancing safety: The Challenge of Foresight. ESReDA Project Group Foresight in safety. European Commission EUR 30441 in cooperation with the European Safety, Reliability \& Data Association.

European Union (2010). Regulation on the Investigation and Prevention of Accidents and Incidents in Civil Aviation and Repealing Directive 94/56/EC, Rule:no 996/ 2010; European Union. Strasbourg: The European Parliament and the Council, p. 16.

Field, R. D., van der Werf, G. R., Fanin, T., Fetzer, E. J., Fuller, R., Jethva, H., et al. (2016). Indonesian fire activity and smoke pollution in 2015 show persistent nonlinear sensitivity to El Niño-induced drought. Proc. Natl. Acad. Sci. U. S. A. 113, 9204-9209. doi: 10.1073/pnas.1524888113

\section{DATA AVAILABILITY STATEMENT}

The original contributions presented in the study are included in the article/supplementary material, further inquiries can be directed to the corresponding author/s.

\section{AUTHOR CONTRIBUTIONS}

AV: writing the first draft. AV, PK, AS, BB, JP, and JS: equally contributed to reviewing and editing to produce the final draft. All authors contributed to the article and approved the submitted version.

Field, R. D., van der Werf, G. R., and Shen, S. S. P. (2009). Human amplification of drought-induced biomass burning in Indonesia since 1960. Nat. Geosci. 2, 185-188. doi: 10.1038/ngeo443

Food and Agriculture Organization of the United Nations (2009). Editors Morgera, E., and Cirelli, M., T. Forest Fires and the Law. A Guide for National Drafters Based on the Fire Management Voluntary Guidelines. Rome: Food and Agriculture Organization of the United Nations.

Giglio, L., Randerson, J. T., and van der Werf, G. R. (2013). Analysis of daily, monthly, and annual burned area using the fourth-generation global fire emissions database (GFED4). J. Geophys. Res. Biogeosci. 118, 317-328. doi: $10.1002 /$ jgrg.20042

Global Fire Emission Database (2021). Available online at: www.globalfiredata.org (accessed April 15, 2021).

Goldstein, B. D. (2012). John Snow, the Broad Street pump and the precautionary principle. Environ. Dev. 1, 3-9. doi: 10.1016/j.envdev.2011.12.002

Hislop, S., Haywood, A., Jones, S., Soto-Berelov, M., Skidmore, A., Nguyen, T., et al. (2020). A satellite data driven approach to monitoring and reporting fire disturbance and recovery across boreal and temperate forests. Int. J. Appl. Earth Observat. Geoinform. 87:102034. doi: 10.1016/j.jag.2019.1 02034

Imam, W. Z., and Aspan, Z. (2020). Legal protection for environmental damage as result of forest and land fires in Indonesia. Eur. J. Mol. Clin. Med. 7, 1166-1176.

Inspector-General for Emergency Management (2020). Inquiry Into the 201920 Victorian Fire Season. Available online at: https://www.parliament.vic. gov.au/file_uploads/Inquiry_into_the_2019-20_Victorian_Fire_Season_ wqcRWCNG.pdf (accessed April 15, 2021).

Insurance Information Office (2021). Available online at: https://www.iii.org/factstatistic/facts-statistics-wildfires (accessed April 15, 2021).

International Civil Aviation Organization (2012). Manual of Civil Aviation Medicine, 3rd Edn. Quebec, Canada: ICAO - International Civil Aviation Organization. Available online at: https:/www.icao.int/publications/ Documents/8984_cons_en.pdf (accessed April 15, 2021).

International Civil Aviation Organization (2016). Aircraft Accident and Incident. Investigation 11th Edition, Annex 13 to the Convention on International Civil Aviation. Quebec: ICAO - International Civil Aviation Organization. Available online at: https://www.kenyoninternational.com/Assets/Downloads/ cos-fa-icao-annex-13-11-ed.pdf (accessed April 15, 2021).

Jang, E., Kang, Y., Im, J., Lee, D.-W., Yoon, J., and Kim, S.-K. (2019). Detection and monitoring of forest fires using himawari-8 geostationary satellite data in South Korea. Remote Sens. 11:271. doi: 10.3390/rs11030271

Jones, C. G., Rappold, A. G., Vargo, J., Cascio, W. E., Kharrazi, M., McNally, B., et al. (2020). Out-of-hospital cardiac arrests and wildfire-related particulate matter during 2015-2017 California wildfires. J. Am. Heart Assoc. 9:e014125. doi: 10.1161/JAHA.119.014125

Kates, R. W., Travis, W. R., and Wilbanks, T. J. (2012). Transformational adaptation when incremental adaptations to climate change are insufficient. PNAS 109, 7156-7161. doi: 10.1073/pnas.11155 21109

Li, W.-C., Braithwaite, G., Wang, T., Yung, M., and Kearney, P. (2020). The benefits of integrated eye tracking with airborne image recorders in the flight deck: a rejected landing case study. Int. J. Indust. Erg. 78:102982. doi: 10.1016/j.ergon.2020.102982 
Li, Z., Nadon, S., and Cihlar, J. (2000). Satellite-based detection of Canadian boreal forest fires: development and application of the algorithm. Int. J. Remote Sens. 21, 3057-3069. doi: 10.1080/01431160050144956

Liu, C., Chen, R., Sera, F., Vicedo-Cabrera, A. M., Guo, Y., Tong, S., et al. (2019). Ambient particulate air pollution and daily mortality in 652 cities. NEJM 381, 705-715. doi: 10.1056/NEJMoa1817364

Makkonen, U., Hellén, H., Anttila, P., and Ferm, M. (2010). Size distribution and chemical composition of airborne particles in south-eastern Finland during different seasons and wildfire episodes in 2006. Sci. Total Environ. 408, 644-651. doi: 10.1016/j.scitotenv.2009.10.050

National Transportation Safety Board (2013). Interim Factual Report. DCA13IA037. Office of Aviation Safety Washington, DC, USA. 20594. Available online at: https://www.prba.org/wp-content/uploads/NTSB-Interim-FactuaReport-March-2013-Dreamliner.pdf (accessed April 15, 2021).

National Transportation Safety Board (2021). Available online at: https://www.usa. gov/federal-agencies/national-transportation-safety-board (accessed April 15, 2021).

Netherlands Aviation Safety Board (1992). Aircraft Accident Report 92-11. El Al Flight 1982. Available online at: https://reports.aviation-safety.net/1992/ 19921004-2_B742_4X-AXG.pdf (accessed April 15, 2021).

New York Times (2020, January 12). Australia's leader calls for inquiry into government response to fires. New York Times. Available online at: https://www.nytimes.com/2020/01/12/world/australia/fires-bushfiresscott-morrison-interview.html (accessed April 15, 2021).

Oliver-Smith, A., Alcàntara-Ayala, I., Burton, I. and Lavell, A., M. (2016). Forensic Investigations of Disasters (FORIN): A Conceptual Framework and Guide to Research (IRDR FORIN Publication No.2). Beijing: Integrated Research on Disaster Risk. 56 pp. Available online at: http://www.irdrinternational.org/wpcontent/uploads/2016/01/FORIN-2-29022016.pdf (accessed April 15, 2021).

Roach, J. (2020). Australia Wildfire Damages and Losses to Exceed $\$ 100$ Billion, AccuWeather Estimates. Available online at: https://www.accuweather.com/ en/business/australia-wildfire-economic-damages-and-losses-to-reach-110billion/657235 (accessed April 15, 2021).

Rogelj, J., den Elzen, M., Höhne, M., Franzen, T., Fekete, H., Winkler, H., et al. (2016). Paris Agreement climate proposals need a boost to keep warming well below $2^{\circ}$ C. Nature 534, 631-639. doi: $10.1038 /$ nature 18307

Silcox, F. A. (1910). Fire Prevention and Control on the National Forests. Available online at: https://foresthistory.org/wp-content/uploads/2017/01/Silcox_Fire_ 1910.pdf (accessed April 15, 2021).

Stefanidou, M., Athanaselis, S., and Spiliopoulou, C. (2008). Health impacts of fire smoke inhalation. Inhal. Toxicol. 20, 761-766. doi: 10.1080/08958370801975311

Stonich, S. (2021). I Am Destroying the Land! New York, NY: Routledge.
Stoop, J. A., and Kahan, J. P. (2005). Flying is the safest way to travel: how aviation was a pioneer in independent accident investigation. The RAND Corporation. EJTIR 5, 115-128. doi: 10.18757/ejtir.2005.5.2.4392

Sulitzeanu-Kenan, R. (2010). Reflection in the shadow of blame: when do politicians appoint commissions of inquiry? Br. J. Politic. Sci. 40, 613-634. doi: 10.1017/S0007123410000049

The House of Committee on Transportation and Infrastructure (2020). Final Committee Report. The Design, Development \& Certification of the Boeing 737 Max. Available online at: https://transportation.house.gov/imo/media/ doc/2020.09.15\%20FINAL\%20737\%20MAX\%20Report\%20for\%20Public \%20Release.pdf (accessed April 15, 2021).

Underwood, P., and Waterson, P. (2013). Systemic accident analysis: examining the gap between research and practice. Accid. Anal. Prev. 55, 154-164. doi: 10.1016/j.aap.2013.02.041

van der Werf, G., R., Randerson, J., T., Giglio, L., van Leeuwen, T., Chen, Y., Rogers, B. M., et al. (2017). Global fire emissions estimate during 1997-2016. Earth Syst. Sci. Data 9, 697-720. doi: 10.5194/essd-9-697-2017

van Lierop, P., and Moore, P. (2016). "International relations for reducing wildfire impacts- some history and some thoughts," in Proceedings of the Fifth International Symposium on Fire Economics, Planning and Policy: Ecosystems Services and Wildfires. Available online at: https://www.fs.fed. us/psw/publications/documents/psw_gtr261en/psw_gtr261_001.pdf (accessed April 15, 2021).

Vuorio, A., Stoop, J., and Johnson, C. (2017). The need to establish consistent international safety investigation guidelines for the chemical industries. Saf. Sci. 95, 62-74. doi: 10.1016/j.ssci.2017.02.003

Xu, R., Yu, P., Abramson, M. J., Johnston, F. H., Samet, J. M., Bel, M. L., et al. (2020). Wildfires, global climate change, and human health. NEJM 383, 2173-2181. doi: 10.1056/NEJMsr2028985

Yu, P., Xu, R., Abramson, M. J., Li, S., and Guo, Y. (2020). Bushfires in Australia: a serious health emergency under climate change. Lancet Planetary Health 4, e7-8. doi: 10.1016/S2542-5196(19)30267-0

Conflict of Interest: The authors declare that the research was conducted in the absence of any commercial or financial relationships that could be construed as a potential conflict of interest.

Copyright (c) 2021 Vuorio, Kovanen, Budowle, Sajantila, Palo and Stoop. This is an open-access article distributed under the terms of the Creative Commons Attribution License (CC BY). The use, distribution or reproduction in other forums is permitted, provided the original author(s) and the copyright owner(s) are credited and that the original publication in this journal is cited, in accordance with accepted academic practice. No use, distribution or reproduction is permitted which does not comply with these terms. 